\title{
Histopathological Study of Infectious Granulomatous Skin Lesions
}

\author{
Ratnakar M Potekar ${ }^{1}$, Anita P Javalgi ${ }^{2 *}$, Lynda Dennis Rodrigues ${ }^{1}$ and Raga Sruthi Dwarampudi ${ }^{1}$ \\ 'Department of Pathology, Shri BM Patil Medical College, Hospital and research centre, Vijayapura-586103, Karnataka, India. \\ ${ }^{2}$ Department of Pathology, SDMCMSH Dharwad, Karnataka, India.
}

\begin{abstract}
Background: Granulomas are the commonest lesions that the pathologists come across in routine practice. Granulomatous inflammation is a distinctive pattern of chronic inflammation that is encountered in a number of infectious and non-infectious conditions. A definitive diagnosis made by demonstration of the etiological agent is essential, which will bear an impact on patient management and outcome.

Methods: This is a retrospective study considering the cases of 2 years. The cases diagnosed as infectious granulomatous skin lesions by clinical presentation, histopathological study of skin biopsies of such patients attending our hospital since July 2010 to July 2012 were included in the study. Clinical history and relevant data were obtained from respective requisition forms of biopsies received.

Results: The study includes 67 cases. A male predominance was noted with 47(70.14\%) cases while females constituted 20(29.85\%) cases. The study shows that $80 \%$ of cases are distributed between 21 to 50 yrs of age while the prevalence of infectious granulomatous dermatoses is highest in the age group of 21-30 yrs. Among the different types of infectious granulomatous dermatoses, leprosy contributed to the major etiology, followed by tuberculosis of skin, leishmaniasis and actinomycosis.

Conclusion: Clinical data with the laboratory workup and special stains together are needed for the definitive diagnosis and management of patients with granulomatous lesions. Cooperation between clinician and pathologist is more important in the field of skin disease than in almost any other field if the patient is to derive the greatest benefit from the biopsy.
\end{abstract}

Keywords: Granuloma, Histopathology, Leprosy, Tuberculosis.

\section{Introduction}

According to Dorland, the term 'granulomatous' was expressed initially by Virchow to describe a tumour like mass or nodule of granulation tissue. ${ }^{[1]}$ But now, granulomatous reaction pattern is defined as focal chronic inflammatory response to tissue injury evoked by a poorly soluble substance characterized by accumulation, proliferation of epithelioid histiocytes, multinucleate giant cells that may or may not be rimmed by lymphocytes and may or may not show central necrosis..$^{[2,3]}$

Granulomatous diseases compromise some of the widespread diseases in the world such as leprosy \& tuberculosis. Granulomatous dermatoses frequently present a diagnostic challenge. An identical histologic pattern may be produced by several causes and conversely a single cause may produce several histological patterns. ${ }^{[4]}$

Five histological types of granuloma can be identified on the basis of the consistent cells and other changes within the granulomas.

1. Tuberculoid

2. Histiocytic

3. Necrobiotic
4. Suppurative

5. Foreign body.

The frequency and types of different granulomatous lesions vary according to geographical locations. ${ }^{[3,4]}$ Infections form an important cause of granulomatous dermatoses with Leprosy and Tuberculosis as the leading etiologies. ${ }^{[5]}$ It is necessary to know an infectious cause of granulomatous skin lesion. Culture of fresh tissue as well as histological search increases the chances of identifying a specific infectious agent. ${ }^{[6]}$

Histopathology plays an important role in classification of Leprosy and in diagnosis and management of a variety of granulomatous skin lesions. Special stains play a supportive role in infectious granulomas. ${ }^{[7,8]}$

The aim of this study is to determine the etiology and study the morphology of all granulomatous skin lesions evaluated histopathologically and to determine relative frequencies of different infectious granulomatous conditions.

\section{Materials and Methods:}

This is a retrospective study of all cases diagnosed clinically as infectious granulomatous skin lesion, whose 
skin biopsies were received for histopathological study in the Department of Pathology, Shri BM Patil Medical College, Bijapur since July 2010 to July 2012. Clinical history and relevant data were obtained from requisition forms of biopsies received.

Diagnosis was mainly made clinically. Skin biopsies were taken as appropriate for routine histological examination. H\&E stain and special stains like Fite Faracco (FF), Peracid Schiff (PAS), Zeihl Neelson (ZN), Gomori Methamine Silver (GMS) were used to study the histopathology of the slides wherever necessary.

\section{Results:}

A total of 67 cases were received, in which male predominance was noted with $47[70.14 \%]$ cases while females constituted 20 [29.85\%] cases. In our study $80 \%$ of cases were distributed between 21 to $50 \mathrm{yrs}$ of age.
The prevalence of infectious granulomatous dermatoses is highest in the age group of 21-30 yrs (Table 1). Leprosy contributed as the major etiology for infectious dermatoses, followed by tuberculosis of skin, leishmaniasis and actinomycosis. (Table 2).

Further morphological categorisation of leprosy in decreasing order revealed 17 cases $(25.37 \%)$ of Borderline Tuberculoid Leprosy, 16 cases $(23.88 \%)$ of Lepromatous Leprosy (Fig. 1 \& 2), 15 cases (22.38 \%) of Indeterminate Leprosy, 7 cases ( $10.44 \%$ ) of Tuberculoid Leprosy, 5 cases $(7.46 \%)$ of ENL and 3 cases $(4.47 \%)$ of borderline lepromatous leprosy. Out of all leprosy cases 19 cases were FF stain positive for lepra bacilli (Table 3 \& Fig 3).

Lupus vulgaris constituted 2 cases (2.98\%) (Fig. 4), leishmaniasis 1 (Fig 5 \& 6) and actinomycosis 1 case.

Table 1: The Prevalence of Infectious Granulomatous Dermatoses in Correspondence to Age and Gender.

\begin{tabular}{|c|c|c|}
\hline Age & Females & Males \\
\hline $1-10 y r$ & 2 & 1 \\
\hline $11-20 y r$ & 3 & 12 \\
\hline $21-30 y r$ & 8 & 9 \\
\hline $31-40 y r$ & 5 & 10 \\
\hline $41-50 y r$ & 1 & 7 \\
\hline $51-60 y r$ & 1 & 0 \\
\hline $61-70 y r$ & 0 & 1 \\
\hline $71-80 y r$ & 0 & 1 \\
\hline $81-90 y r$ & 0 & $\mathbf{4 7 ( 7 0 . 1 4 \% )}$ \\
\hline Total & $\mathbf{2 0 ( 2 9 . 8 5 \% )}$ & \\
\hline
\end{tabular}

Table 2: Showing the contribution of each etiology of cutaneous granulomas.

\begin{tabular}{|c|c|c|}
\hline Type of infectious granulomatous dermatoses & No.of persons & Percentage (\%) \\
\hline Types of leprosy & & 25.33 \\
\hline Borderline Tuberculoid Leprosy & 17 & 23.88 \\
\hline LepromatousLeprosy & 16 & 22.38 \\
\hline Indeterminate Leprosy & 15 & 10.44 \\
\hline Tuberculoid Leprosy & 7 & 7.46 \\
\hline ENL & 5 & 4.47 \\
\hline Borderline Lepromatous Leprosy & 3 & \\
\hline Other than Leprosy & & 2.98 \\
\hline Lupus Vulgaris & 2 & 1.49 \\
\hline Leishmaniasis & 1 & $100 \%$ \\
\hline Total & $\mathbf{6 7}$ & \\
\hline
\end{tabular}

Table 3: Showing the positivity of the slides for fite faraco.

\begin{tabular}{|c|c|}
\hline Stain & No.of cases \\
\hline Fite Faraco stain positive & 19 \\
\hline Fite Faraco stain negative & 36 \\
\hline
\end{tabular}




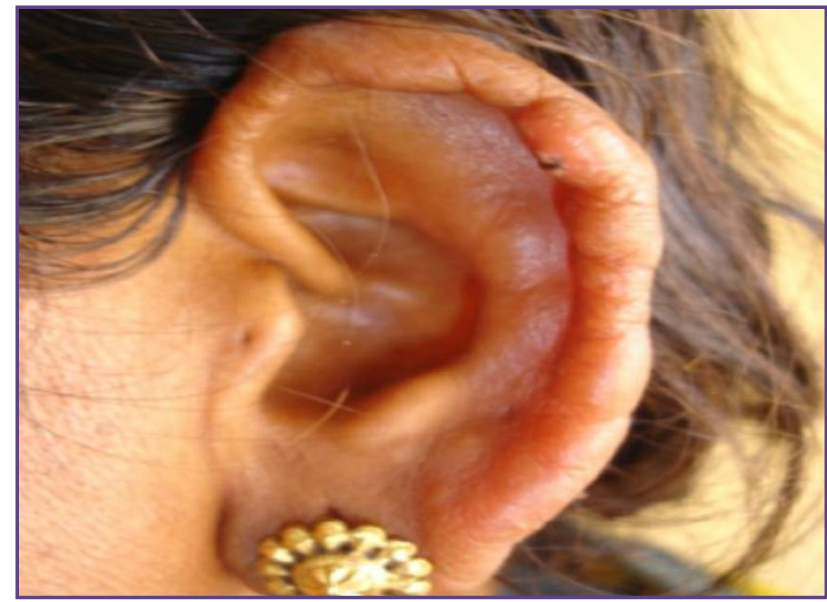

Fig. 1: Clinical photograph of lepromatous leprosy showing nodular thickening of ear lobules.

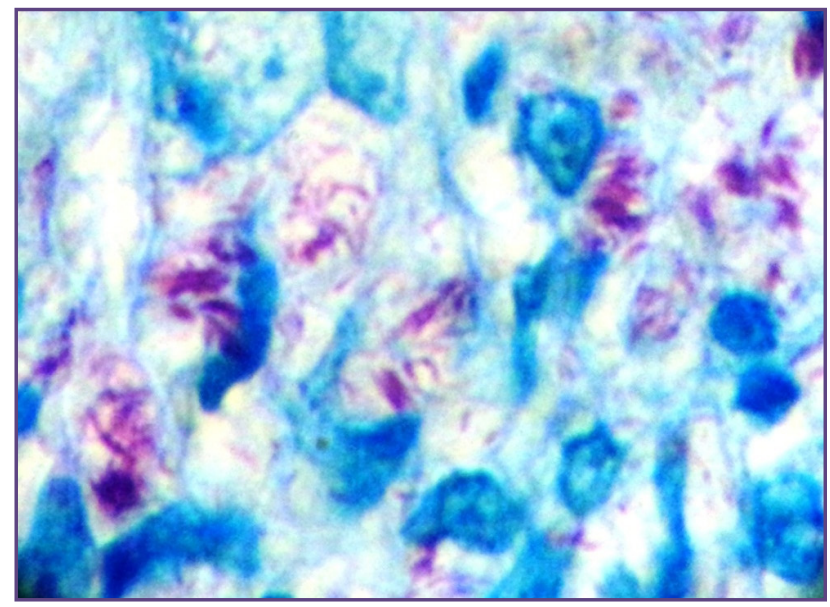

Fig. 3: Fite Faraco stain section of Lepromatous leprosy showing foamy histiocytes laden with lepra bacilli in bundles (1000X).

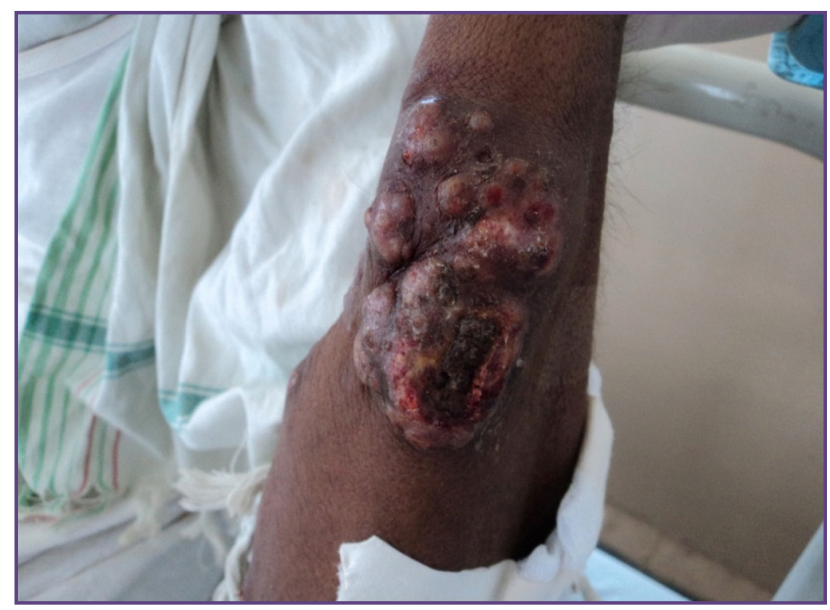

Fig. 5: Clinical photograph of cutaneous leishmaniasis presenting as nodulo- ulcerative lesion over forearm.

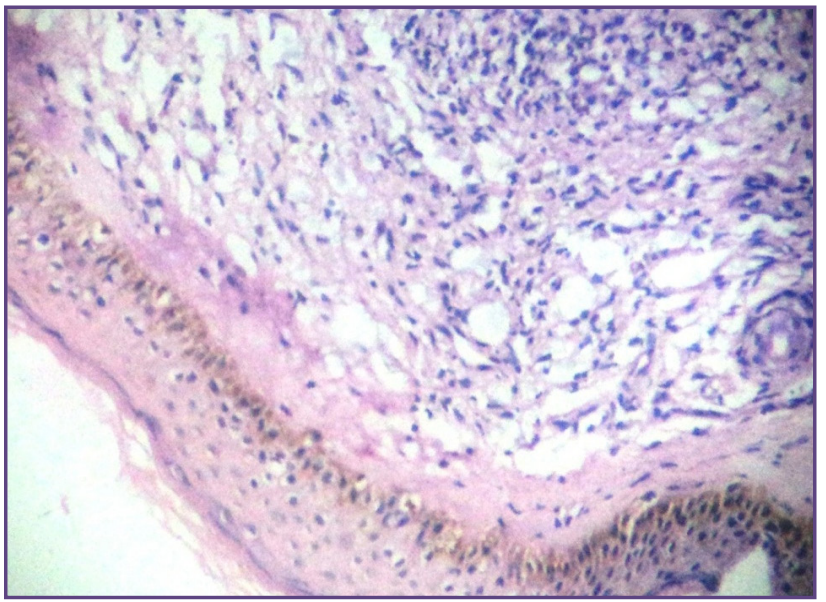

Fig. 2: H\& E Section of Lepromatous leprosy showing foamy histiocytes with lymhocytic infiltrate (100X).

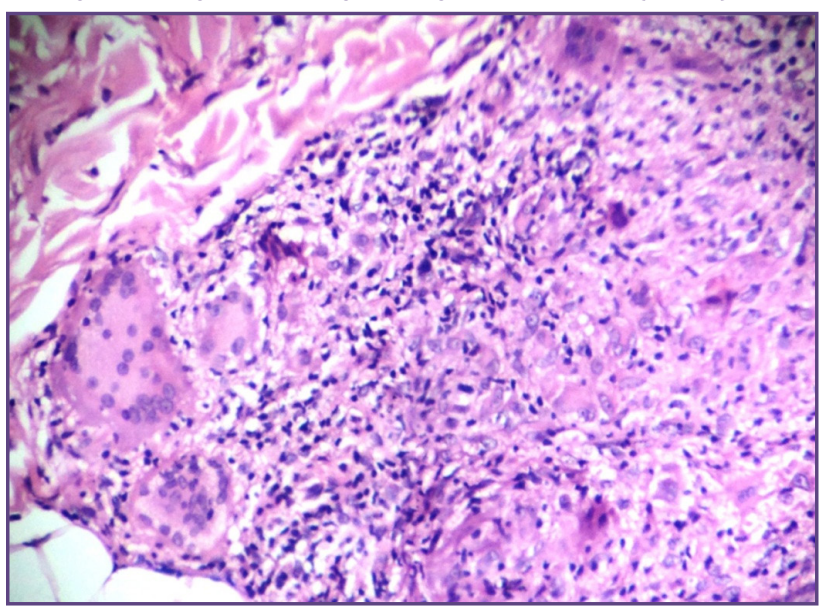

Fig. 4: Lupus vulgaris: H\& E Section showing epitheloid granuloma with lymphoplsmacytic infiltrate and Langhan's giant cells. (400X).

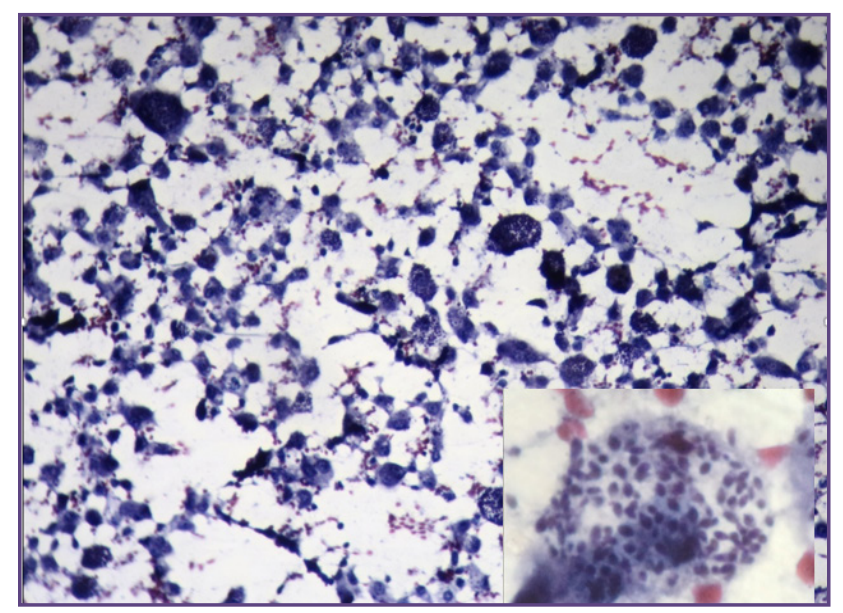

Fig. 6: Microphotograph showing Giemsa stained smear with necrotic debris \& many hisiocytes containing Leishmann Donovan bodies.(100X) Inset (400X). 


\section{Discussion}

Granulomatous inflammation was recognized as a distinct entity in the early nineteenth century and has been of continuing interest since then. Arrival at a proper diagnosis is mandatory so that appropriate treatment can be mete out. ${ }^{9}$ Histopathology remains a time-tested tool for establishing a correct diagnosis like in many other diseases pertaining to various organ systems of the body. ${ }^{[5]}$

A large number of individual studies on granulomatous lesions of skin were found but still no comprehensive comparative study was found on various granulomatous lesions of skin in our region except Morphological study of different granulomatous lesions of the skin done by Zafar M et al in 2002..$^{[5]}$

The distribution of cutaneous granulomatous lesions varies widely depending on geographic locations. The studies by Gautam et $a l^{7}$ includes infectious \& non infectious causes presenting as cutaneous granulomas. Very few studies have specifically studied the infectious cutaneous granulomatous lesions, so there is wide statistical variation for various lesions.

The present study shows infectious granulomas with male predominance in $70.14 \%$ cases as compared to $29.85 \%$ females. Mh El Khalwaney ${ }^{[9]}$ reported $40.8 \%$ cases of cutaneous tuberculosis followed by leprosy (31.7\%). A. $\mathrm{Bal}^{3}$ noted leprosy as leading cause of cutaneous granuloma while Rubina Qureshi et $a^{[10]}$ reported cutaneous leishmaniasis in $56.7 \%$ of cases followed by lupus vulgaris in $13.5 \%$ cases. The results of our study are comparable with the results of Indian study done by A. Bal et al. ${ }^{5}$

The finding that the major etiology of infectious granulomatous dermatoses in our study is leprosy and among the morphological classification of leprosy, borderline tuberculoid leprosy and indeterminate leprosy are in accordance with the studies of Bal et $\mathrm{al}^{5}$ and Gautam et $a l^{7}$.

The present study included 5 cases (7.46\%) of ENL which is in concordance with studies done by $\mathrm{Bal} \mathrm{A}$ et $a l^{5}$ that reported 8 cases, $(2.1 \%$,) of ENL and 9 cases $(2.4 \%)$ of downgrading/upgrading reaction.

The present study also shows 2 cases of cutaneous tuberculosis presenting as lupus vulgaris. Both of these cases were negative for Acid fast bacilli by $\mathrm{ZN}$ staining. Demonstration of acid fast bacilli by ZN stain is specific; however positivity varies with different studies. Study done by A.Bal ${ }^{4}$ has reported $5 \%$ positivity in lupus vulgaris and upto $6.5 \%$ positivity in scrofuloderma.

The present study includes 1 case of leishmaniasis presenting as nodulo-ulcerative lesion. The diagnosis of this case was established by demonstrating L-D bodies in fine needle aspiration cytology (FNAC) while H\&E sections revealed only nonspecific granulomas. Clinical lesions of post kalaa-zar dermal leishmaniasis (PKDL) commonly confuses with those of lepromatous leprosy. Histopathological examination for type of infiltrate and Giemsa stain for LD bodies can resolve the problem. It is usually difficult to detect LD bodies in paraffin sections, but plasma cellhistiocytic inflitrate can suggest the diagnosis. ${ }^{[10,11,12,13]}$ Leishmaniasis is less common in this part hence strong clinical suscipicion with various diagnostic modalities helps in the proper diagnosis.

The present study didn't revealed any case of fungal granulomas. Literature has reported incidence of fungal cutaneous granulomas in the range between $2.7 \%$ to $3.3 \%$. $[5,7,10,12,14,15]$

\section{Conclusions}

Of the total skin biopsies received at our institution within 2 years, 67 cases were diagnosed as infectious granulomatous dermatoses with a ratio of prevalence of the infectious granulomatous dermatoses between males and females being 2.42:1. The major etiology of cutaneous granuloma is leprosy with borderline tuberculoid leprosy and indeterminate leprosy as the most common type and Lupus vulgaris is the common form of cutaneous tuberculosis.

In order to apply the knowledge effectively when examining biopsy sections, it is essential that submitting physicians provide detailed clinical information. Clinical diagnosis or a list of differential diagnosis should be given. Clinical data with the laboratory workup and special stains together are necessary for the diagnosis and management of the patients. Cooperation between clinician and pathologist is more important in the field of skin disease than in almost any other field if the patient is to derive the greatest benefit from the biopsy.

\section{Acknowledgement}

We would like to thank Dr Yelikar BR, Head of department of pathology, Shri BM Patil Medical College, Vijayapura for encouraging and supporting this study. We would also like to extend our special thanks to all the technical staff of the Department of pathology, Shr. BM Patil Medical College, Hospital and Research Centre for all the help and cooperation rendered during this study.

\section{References}

1. Bernard C. Hirsh \& Waline C. Johnson. Concepts of Granulomatous Inflammation. International Journal of Dermatology.1984; 23: 90-100.

2. Kumar V, Abbas AK, Fausto N, Aster JC .Acute And Chronic Inflammation. In Robbins And Cotran's . Pathologic Basis of Disease. 8th Edition: New Delhi; Elsevier India. 2010: 73-4. 
3. Permi H, Shetty JK., Shetty KP, Teerthanath S, Mathias M, Kumar YS , Prasad H.L. , Chandrika A Histopathological Study Of Granulomatous Inflammation. Nitte University Journal of Health Science.2012; 2(1): 15-9.

4. Zaim MT, Bordell RT, Pokorney Dr. Non Neoplastic Inflammatory Dermatoses: A Clinicopathologic Correlative Approach. Mod Pathology.1990;3:381-414.

5. Amanjit B, Harsh M, GP Dhami. Infectious Granulomatous Dermatitis. Indian Journal of Dermatology. 2006;51(3):217-20.

6. Weedon D. The Granulomatous Reaction Pattern In: Skin Pathology.2nd Edition; New York: Churchill Livingstone; 2000: 94-213.

7. Gautam K, Pai RR, S Bhat. Granulomatous Lesions of Skin. Journal of Pathology of Nepal 2011; 1(2):81-86.

8. Lockwood DN, Nicholas P, Smith WC, Das L, Barkataki P , Van BW, Suneetha S. Comparing The Clinical And Histological Diagnosis Of Leprosy And Leprosy Reactions In Infir Cohort Of Indian Patients With Multibacillary Leprosy.Plos Neglected Tropical Diseases ,6(6),E1702.

9. Mohammed EL K, Ibrahin M, Bayoumi E, Hussein H El N, Clinicopathological Features \& The Practice of Diagnosing
Infectious Cutaneous Granulomas In Egypt. International Journal of Infectious Diseases. 2011; 15: 620-6.

10. Rubina Q, Riyaz A S, Anwar U1 H. Chronic Granulomatous Inflammatory Disorders of Skin At A Tertiary Care Hospital In Islamabad. International Journal of Pathology; 2004; 2(1): 31-4.

11. Wayne Gr, Eduward C \& Philip M. Infectious Diseases of The Skin in Pathology Of Skin With Clinical Correlations 3rd Ed Vol. 1elsievier Mosby. 2005: 837-991.

12. T J Stephenson Inflammation: General \& Systemic Pathology 5th Edition;Edinburgh: Churchill Livingstone.2009: 216-19.

13. Arfan Ul B, Shehzad A, Amer E, Tariq M. Comparison of Various Cytodiagnostic Tests in Rapid Diagnosisof Cutaneous Of Leishmaniasis. Journal of Pakistan Association of Dermatologists.2010; 20: 63-9.

14. Sebastian L, Klaus S, Eckart H. Bacterial Diseases, Protozoan Diseases \& Parasitic Infestations in Lever's Histopathology Of Skin 10th Edition, New Delhi; Lippincott Willimas \& Wilkins .2009;550-572 \&621-4.

15. Nayak SV, Shivrudrappa AS, Mukamil AS. Role of fluorescent microscopy in detecting Mycobacterium leprae in tissue sections. Annals of diagnostic pathology 2003 April; 7(2): 78-81.

*Corresponding author:

Dr. Anita P Javalgi, Department of pathology, Shri BM Patil Medical College, Bangaramma Sajjan Campus, Vijayapura- 586103, Karnataka, India

Phone: +919590196666

Email: anitajawalgi@gmail.com

Financial or other Competing Interests: None. 